
\title{
Reseacch Soute \\ Resilient care of the patient with COVID-19 in Iran: A phenomenological Study
}

\section{Parvaneh Asgari}

Tehran University of Medical Sciences

\section{Alun C Jackson}

Australian Heart Health Center

Fatemeh Bahramnezhad ( $\square$ bahramnezhad.f@gmail.com )

Tehran University of Medical Sciences https://orcid.org/0000-0002-2015-0204

\section{Research article}

Keywords: Coronavirus, COVID-19, Qualitative research, Phenomenological, Family Caregiver

Posted Date: June 2nd, 2020

DOI: https://doi.org/10.21203/rs.3.rs-24733/v1

License: (c) (i) This work is licensed under a Creative Commons Attribution 4.0 International License. Read Full License 


\section{Abstract \\ Background}

Family caregivers understand several challenges in caring for patients with COVID-19. This study aimed to understand the experiences of Iranian family caregivers of persons with COVID-19.

\section{Method:}

This study utilized phenomenological hermeneutic design. Fourteen Iranian family caregivers of patients with COVID-19 who were quarantined at home were included in the study using purposive sampling. Indepth semi-structured interviews were conducted via WhatsApp. Sampling continued until data saturation. Interviews were transcribed and analyzed using Van Manen's approach.

\section{Result}

Three primary themes and eight subthemes emerged. The primary themes included: "captured in a whirlpool of time", "resilient care' and "feeling helpless".

\section{Conclusion}

It seems that the families of patients with COVID-19 attempt to resist the pressures of this disease with religious practices and problem solving. However, due to the nature of the disease and its severity, they sometimes feel ashamed or lonely and are afraid of losing their loved ones. It is recommended that psychiatric nurses should develop programs in the form of comprehensive spiritual care packages or psychological support and utilize multiple media channels to deliver these.

\section{Background}

In September, 2019, new respiratory virus known as SARS-CoV-2 or COVID-19 spread quickly from Wuhan, China and was declared a health emergency by the World Health Organization (WHO)[1, 2]. COVID-19 is caused by the Severe Acute Respiratory Syndrome Coronavirus-2 (SARSCoV-2). This novel singlestranded enveloped RNA virus is the seventh known human coronavirus and is similar to the zoonotic severe acute respiratory syndrome coronavirus (SARS-COV) from 2002 (SARS) and the Middle East respiratory syndrome coronavirus (MERS-COV) from 2012 (MERS)[3].

Currently, more than 200 countries are involved in this crisis. The number of patients in Iran suffering from COVID-19, as of April 3rd includes 20,000 patients with 2,234 deaths. The high rate of COVID-19 infections has caused fear and anxiety in affected countries [4]. According to International Health Commission guidelines, groups in need of psychological support include suspected or diagnosed 
patients, healthcare staff, families, and people who avoid treatment [5]. The primary objective of healthcare measures is prevention of person to person transmission through isolating people and cutting the transmission chain [6]. In order to prevent further transmission and the influx of a significant number of people to medical centers, after monitoring the health and clinical risks of patients with mild or no symptoms who are reliable and educable, and observing all due diligence, treatment at home is recommended. Quarantining in the home is one of the oldest and most effective control measures for epidemic diseases [1, 7]. In Iran, the Ministry of Health has recommended that people with COVID- 19 who do not have severe symptoms be quarantined at home. Contact the 4030 (A telephone system for patients with COVID-19) if medication is needed or symptoms worsen. Do not leave the house at all. At home, they are instructed on how to care for their family.

Home care, referred to as hospital in the home or the wall-less hospital involves provision of medical services at home to reduce hospital complications, shorten length of stay, increase efficiency in the use of hospital beds, and reduction of waiting lists without compromising the quality of care[8]. Family basedcare involving changes to traditional roles, is a vital component in increasing care quality and optimizing patient outcomes [9]. The family caregiver is primarily responsible for caring for the patient hospitalized at home[10]. When patients are isolated, they face new challenges such as loneliness, fear of death, and disease transmission to others. Communication with family members is a critical source of social and emotional support for patients. In these situations, the family, as a member of the treatment team, fights the disease on the front line. To do so effectively, patients and family members need psychoeducational input including personal health and hygiene, correct nutrition, and prevention and control measures[11]. Family caregivers face a range of challenges such as dealing with uncertainty about outcomes, change in roles, facing new responsibilities as a care provider and fear of becoming sick themselves[11, 12]. In these circumstances, lack of sufficient and clear information, and in the case of a highly infectious condition such as COVID-19, and lack of protective equipment leads to feelings of vulnerability and insecurity, and confidence on their own capacity in families [13]. As shown in a Chinese study, within the first days of this disease, stress and anxiety levels in the society were moderate to high and psychological interventions were needed to promote the mental health of endangered groups [14]. To reduce stress and anxiety of patients and families, a relationship needs to be established early with preferably, a multidisciplinary treatment team [15]. To explore the experiences and challenges of home care for family caregivers regarding COVID-19 as a global pandemic, a phenomenological study is proposed.

Phenomenology is a philosophy and a research method that focuses on live experiences. This method facilitates a deeper understanding of complex social phenomena and attempts to provide a description of phenomena as experienced[16]. This study aimed to explore the lived experiences of family caregivers who care for patients with COVID-19 with which to understand the inherent structure of this phenomenon and the real world of family caregivers as described by them in conveying their lived experience.

\section{Method}


This study is utilized a phenomenological hermeneutic design using the Van Manen method as described below[17]. Data were collected from April to March 2020.

\section{Participants}

A purposive sample was drawn from family caregivers who had experience of caring from patients with COVID-19 and willingness to participate in research.

Twenty interviews with 14 family caregivers of people who had tested positive for COVID-19 and were being cared for at home, were held. .The Mean age (SD) of these participants was $39.34( \pm 11.04)$. The interviews lasted between 45 and 60 minutes. It should be noted that due to the quarantine and to prevent the spread of the virus, no in-person interviews were conducted. The first author of the article made a phone call to the family caregiver based on the list of patients who had coronavirus at home. She stated the aims of the study, and, if agreed, the corresponding author would contact via What's-App or Skype at a time suitable for the caregiver. In some cases, follow up phone calls were made to clarify questions arising. Sampling continued until data saturation was achieved, when the researchers perceived that no new themes were emerging.

\section{Data Collection}

After explaining the goals and significance of the research to the participants, the steps in the research process were outlined and before starting the interview informed consent was obtained. Permission was also obtained to record interviews and participants were assured that the obtained information would be used only for the purposes of the research and would remain confidential. Participants were also informed that withdrawal from the study would not compromise their treatment. To collect data, unstructured in-depth interviews were used based on the native language of the participants (Farsi). The interview started with the general question "Please explain your experiences in the caring of patients with positive coronavirus" and then, exploratory questions were asked to encourage the participants and to achieve a greater depth of information. Interviews were recorded with the permission of the participants. The interviews were transcribed.

\section{Data Analysis}

The interviews were analyzed using the principles of phenomenological hermeneutics as developed by Van Manen (2001). This qualitative approach was selected because it gives a high level of access to participants' lived experience[17].

Van Manen (2001) believes that interpretive phenomenology is a systematic approach for exploring and interpreting structures of internal meanings and lived experience allowing for the desired phenomenon to be analyzed and explored with an interpretive approach[17]. It is necessary to note that Van Manen (2001) has introduced six methodological approaches as a practical approach in interpretive phenomenology [18]. In this study, we used four of the six van Manen approaches to analyses the data(Table 1). The interviewer started with an extensive and general question about the experience of taking care of patients with COVID-19 followed by exploratory questions to encourage the participant and 
gain access to deeper information. Interviews continued until this 'deep data' was accessed. The interviews were recorded with permission of the participants and immediately after completion of the interviews they were transcribed and the text subjected to repeated reading.. In this research task, a holistic and selective approach was used to separate sentences in which sentences or terms which seemed to be related to the phenomenon of interest (caring for a COVID-19 infected family member), were selected (selective approach). The sentences identified by this method were selected, converted and transformed for each interview (experimental or primary theme). The primary themes and subthemes were identified through the use of experts' and specialists' views for confirming the themes. This process is outlined in Table 1.

Table 1

Data analysis activity

\begin{tabular}{|c|c|c|}
\hline Activities & Description & $\begin{array}{l}\text { Measures taken in the } \\
\text { study }\end{array}$ \\
\hline \multirow[t]{3}{*}{ Third } & $\begin{array}{l}\text { Third activities: Hermeneutic reflection: The researcher reflects } \\
\text { on the lived experience to grasp its special significance. }\end{array}$ & $\begin{array}{l}\text {-Transcription were } \\
\text { read several times }\end{array}$ \\
\hline & & $\begin{array}{l}\text { - Short descriptions } \\
\text { were written by using } \\
\text { a holistic approach }\end{array}$ \\
\hline & & $\begin{array}{l}\text { - Clusters of themes } \\
\text { were merged and } \\
\text { these classifications } \\
\text { were named }\end{array}$ \\
\hline \multirow[t]{2}{*}{ Fourth } & $\begin{array}{l}\text { Fourth activities: Hermeneutic writing: The researcher describes } \\
\text { the phenomenon through writing and rewriting. }\end{array}$ & $\begin{array}{l}\text { - Collaborative } \\
\text { analysis was } \\
\text { performed }\end{array}$ \\
\hline & & $\begin{array}{l}\text { - Free imaginative } \\
\text { variation was used }\end{array}$ \\
\hline \multirow[t]{2}{*}{ Fifth } & $\begin{array}{l}\text { Fifth activities: Maintaining a strong and oriented relation with } \\
\text { the phenomenon: The researcher fully, not superficially, } \\
\text { understands the phenomenon }\end{array}$ & $\begin{array}{l}\text { - Constant review of } \\
\text { the main research } \\
\text { question }\end{array}$ \\
\hline & $\begin{array}{l}\text { Sixth activates: Balancing the research context by considering } \\
\text { parts and whole: This requires a serious return to data, while } \\
\text { checking how the component parts contribute to the whole } \\
\text { picture. }\end{array}$ & $\begin{array}{l}\text { - Combination of two } \\
\text { selective and holistic } \\
\text { approaches }\end{array}$ \\
\hline
\end{tabular}

\section{Trustworthiness}

To ensure rigor in the study we drew on Lincoln and Guba's (1985) criteria for establishing trustworthiness in qualitative research: confirmability, credibility, transferability, and dependability[19].

To ensure credibility, or confidence in the 'truth' of the findings, the findings were given to the participants who were given the opportunity to express their views about the extent to which the research team's interpretation of their experience conformed with their view of their experiences. 
The researchers ensured confirmability by documenting all stages of the research so that an independent observer could confirm that the meaning extracted from the data was shaped by the data itself and not by the bias, motivation or interest of the researchers. The immersion of the researchers in the studied phenomenon, long-term contact with the data and efforts to gain the views of others in this field contributed to meeting the criterion of confirmability.

\section{Result}

The main objective of this study was to explore the experiences of family caregivers who care for patients with COVID-19 at home to obtain a deep and rich insight about this phenomenon. The themes that emerged from family caregivers are answers to the primary question, "Please explain your experiences in the caring of patients with positive coronavirus" Twenty five themes emerged from 160 subthemes which were integrated into three main themes and eight subthemes, with the main themes being: "caring for a patient means captured in a whirlpool of time", "resilient care" and "feeling helpless.".

\section{Captured In A Whirlpool Of Time}

This was the first theme identified, in family members' caring for patients with COVID-19. It included the two subthemes of "remembering past life" and "fear of the future". These themes reflect the fact that caring for a family member patient involved positive reflection on a peaceful past which contrasted with a fearful and unknown future, and the prospect of not being able to re-experience that positive past. Caught between a positive past and an uncertain future, the family caregiver becomes fearful and worried and experiences loss of energy and low mood.

\section{Remembering past life}

Participants spent time reviewing memories and in the care-giving period looked at family pictures and films and reviewed memories with their family member patient, often expressing regret that they did not spend more time together.

Participant number 2 who was caring for her 68-year old mother with coronavirus for 10 days said:

I always remember good old days. Everything was good. On Fridays, we were gathering at her home and spending good time until the midnight.

Participant number 9 who was caring for her husband for 3 days stated:

These days, I checked old photos. I sit behind his room door and we talk about past memories.

Fear of the future

According to the family caregivers caring for patients with coronavirus, this activity is accompanied by fear of the future. This fear has various aspects such as "fear of getting worse", "fear of death", and "fear 
of getting the disease".

The participants stated that due to the unfolding nature of the pandemic, they were uncertain and scared of the future. If the patient gets sicker, what should they do? This is the fear of loss and death of their loved ones. In this regard, a 39-year old woman caring for her father stated:

With these situations, it is not clear what will happen. I am scared of the future if my father gets worse and forcing me to take him to the hospital.

Participant number 11, a 29 year-old man caring for his wife at home stated:

I cannot live without my wife even for a second. I am scared of the future and what will happen to her.

Moreover, a major concern of the participants was fear of other family members, including themselves, of becoming infected.

"In addition to the concerns for my husband, I'm worried that my son will get the coronavirus too." (Participant 6).

\section{Resilient Care}

Participants stated that although they faced the problems associated with care they recognized that some factors were out of their control and they needed to find safe solutions for the things they could control, using goal setting and problem-solving approaches. In this regard, goals such as family reunion and returning to normal life helped the career by providing them with hope. In addition, according to the beliefs of the participants, nothing occurs without reason, and this is a system determined by God. This divine fate has been taken into consideration by the participants from two perspectives.. Some people consider it a gift by God and others believe that these events are aimed at awakening people and are an opportunity for people to both compensate for the past to be prepared for the present situation.. Three subthemes emerging in this theme are "purposeful life", "self-esteem", and "acceptance of fate" (Table 2). 
Table 2

Subthemes of resilient care

Resilient Subtheme Statements

care

\begin{tabular}{|c|c|}
\hline Purposefulness & $\begin{array}{l}\text { A } 33 \text { year- old woman caring for her husband for } 5 \text { days stated: } \\
\text { I repeatedly tell myself that we should be together again. I should not } \\
\text { give up. }\end{array}$ \\
\hline \multirow[t]{3}{*}{ Self-esteem } & "I can and I repeat it all the time. I do not give up." (Participant 1) \\
\hline & Participant number 14 , caring for his brother stated: \\
\hline & $\begin{array}{l}\text { I am different from my sisters and brothers because I was always } \\
\text { independent and could take advantage of the worst conditions. For } \\
\text { this reason, I care for my brother because I know that I can. }\end{array}$ \\
\hline
\end{tabular}

Acceptance of A 23-year old midwife caring for her father at home stated:

fate

Everything by God has a reason and this is a gift that tells me God loves me and wants to see how strong I am.

A 45 year-old man caring for his 12 -year old boy due to Duchenne muscular dystrophy (DMD) and his wife suffered from COVID-19 stated:

I was so ungrateful. God sent this to tell me I am watching you and move yourself.

\section{Feeling Helpless}

The third theme that emerged in this study was "feeling helpless" with two subthemes of "Ioneliness" and "a sense of shame". A part of this loneliness experience is due to careers, to protect other family members and friends against getting the virus, isolating themselves due to a fear of others becoming infected. People exercising this caution often do not feel that people are sympathetic to their circumstances, and they feel a sense of helplessness and loneliness. The second sub-theme that leads to a sense of helplessness in the individual. It is a shame that a person has realized that his family member is infected. In fact, he understands the disease in a range from lack of hygiene to guilty. For this reason, she has separated herself from others, and this loneliness and shame have fueled her sense of helplessness.

Maryam is a $\mathrm{PhD}$ candidate in math caring for her parents at home:

I had to tell my brother and his wife not to come here. It been 8 days that nobody has met us and this is for them but at least, they could call!

Participant 10 said:

I told nobody that my husband is sick because they would say he does not wash his hands or maybe he has done something bad and now he is experiencing the consequences! 


\section{Discussion}

This study has shown that despite the many problems that family caregivers experience in caring for patients with COVID-19, they are able to provide resilient care for these patients. The first theme that emerged in this study was being captured in a whirlpool of time experiencing both positive memories of their past life and fear of the future. Family caregivers, due to fear of losing the patient or contracting the virus themselves, were caught in this tension between memories and the future. Perhaps memories come to the fore because these people suddenly face a threatening situation and a fear of death and loss of their loved ones. No study was found that explicitly talks about this theme in relation to other emergent diseases. Studies by Navab et al. and Shafie et al. on the experiences of family caregivers who were caring for patients with Alzheimer's Disease, pointed out that caregivers were experiencing this tension between memories fear of the future, particularly in relation to getting the disease themselves in the future $[20,21]$.

The second theme that emerged in this study was resilient care with participants stating that purposefulness, self-esteem, and acceptance of fate facilitates stress management and attempts at recovery. Lin et al. in a study on the resilience of parents with children with chronic diseases, identified acceptance of fate as an important factor in developing resilience in caring for their children[22]. Bandstatter et al. identified purpose and meaning in life as important factors in stress management in family caregivers who care for end-of-life patients [23]. In relation to the third theme in this study, that is feeling helpless and experiencing loneliness leading to a sense of shame, this may be a product of social rejection externally or of a fear of contracting the virus, an intrinsic motivator for isolation. Many people are not familiar with the nature of this disease and this makes them distance themselves from a patient with COVID-19. Perhaps in Eastern culture, infection is stigmatized as the patient not respecting their health and not following good hygiene practices such as washing their hands. In this regard, the researchers did not find any study on lack of sympathy by others in considering the care of a patient with a chronic disease although a South Korean study on the experiences of nurses caring for patients with MERS, nurses experienced a sense of loneliness in caring for these patients[24]. This sense of loneliness has also been found in caring for older people [25], patients with cancer [26, 27], and patients with Parkinson's Disease [28]. In relation to shame, Navab et al. in a study on patients with Alzheimer's Disease stated that because of patient behavior caregivers can become embarrassed with this leading to them isolating themselves [29]. One reason that no study exists on the experiences of family caregivers on patients with chronic disease in the Iranian context may be that it has not been common to care for patients with chronic conditions at home. Usually, these patients are treated in hospital and receive care from a healthcare team.

\section{Conclusion}

This appears to be the first time that a disease has intensively involved Iranian people having to care for their family member patients at home and in isolation. People have been taken by surprise by this unknown virus and the speed of its spread and highly infectious nature and the psychological 
atmosphere dominating society faces people with a real fear of losing their beloved ones. Quarantine and the limitations placed on interpersonal relationships creates a sense of loneliness and may lead to feelings of shame. However, having a purpose and goal of recovery and family reunion; placing this CODVID-19 experience within a spiritual framework; and building self-esteem through caring for these patients, can help caregivers to develop resilience about this disease and enhance their caring capacity. It is recommended that psychiatric nurses should develop programs in the form of comprehensive spiritual care packages or psychological support and utilize multiple media channels to deliver these.

\section{Abbreviations}

COVID-19

Corona Virus Disease2019

WHO

World Health Organization

SARSCOV-2

Severe Acute Respiratory Syndrome Coronavirus-2

MERS

Middle East respiratory syndrome coronavirus (MERS-COV)

\section{Declarations}

\section{Ethics approval and consent to participate}

This study was approved by the Ethics Committee of Tehran University of Medical Sciences, Tehran, Iran (No:97-02-99-38302). All participants in the study signed an informed consent and sent for the researcher (Correspondence) via What's-Ap.

\section{Consent for publication}

Not applicable

\section{Availability of data and materials}

Not applicable

\section{Competing interests}

The authors declare that they have no competing interests

\section{Funding}

Not applicable

\section{Authors' contributions}


FB conceived of and designed the study, Interviewed with participant, coded interview and drafted manuscript. ACJ supervised the study and approved the manuscript. PA coded interview and she was involved in writing the original draft of the manuscript. All of the authors have approved the final manuscript.

\section{Acknowledgements}

This research has been supported by Tehran University of Medical Sciences, Tehran, Iran (No IR.TUMS.VCR.REC.1399.004). The authors are deeply grateful to the participants for sharing their experiences.

\section{References}

1. Li D. hallenges and responsibilities of family doctors in the new global coronavirus outbreak. Family Medicine Community Health. 2020;8(e000333):doi:10.1136/fmch-2020-000333.

2. Li X, Guo Z, Li B, Zhang X, Tian R, Wu W, et al. Extracorporeal Membrane Oxygenation for Coronavirus Disease 2019 in Shanghai, China. ASAIO journal (American Society for Artificial Internal Organs: 1992). 2020.

3. Chan JW, Ng CK, Chan YH, Mok TY, Lee S, Chu SY, et al. Short term outcome and risk factors for adverse clinical outcomes in adults with severe acute respiratory syndrome (SARS). Thorax. 2003;58(8):686-9.

4. Liu X, Kakade M, Fuller CJ, Fan B, Fang Y, Kong J, et al. Depression after exposure to stressful events: lessons learned from the severe acute respiratory syndrome epidemic. Compr Psychiatr. 2012;53(1):15-23.

5. Duan L, Zhu G. Psychological interventions for people affected by the COVID-19 epidemic. The Lancet Psychiatry. 2020.

6. Zhu N, Zhang D, Wang W, Li X, Yang B, Song J, et al. A novel coronavirus from patients with pneumonia in China, 2019. New England Journal of Medicine. 2020.

7. WHO.. Home care for patients with Middle East respiratory syndrome coronavirus (MERS-CoV) infection presenting with mild symptoms and management of contacts: interim guidance. World Health Organization; 2018: 2.3.2020; 2018 [.

8. WHo. Home care for patients with suspected novel coronavirus ( COVID-19) infection presenting with mild symptoms, and management of their contacts: interim guidance, 04 February 2020 . World Health Organization; 20202020 [.

9. Bohlin K, Lilliesköld S. Family-Centered Care: Nice to Have or a Real Need? Innovations Frontiers in Neonatology 22: Karger Publishers. 2020;1(1):159-68.

10. Dale C, King J, Nonoyama M, Carbone S, McKim D, Road J, et al. Transitions to Home Mechanical Ventilation. The Experiences of Canadian Ventilator-assisted Adults and Their Family Caregivers. Annals of the American Thoracic Society. 2018;15(3):357-64. 
11. Cates DS, Gomes PG, Krasilovsky AM. Behavioral Health Support for Patients, Families, and Healthcare Workers. In: Hewlett A, Murthy K AR, editors. Bioemergency Planning: A Guide for Healthcare Facilities. Cham: Springer International Publishing; 2018. pp. 195-214.

12. Marçal V, Wiese M, Dal P, Grah B, Mioto R-. Cuidadoras Domiciliares em Saúde e Responsabilização Familiar: as vozes quase nunca ouvidas (Home caregivers in healthcare and family responsibility: voices rarely heard). Emancipação. 2020;1(20):13-20.

13. Wu KK, Chan SK, Ma TM. Posttraumatic stress, anxiety, and depression in survivors of severe acute respiratory syndrome (SARS). Journal of traumatic stress. 2005;18(1):39-42.

14. Wang C, Pan R, Wan X, Tan Y, Xu L, Ho CS, et al. Immediate Psychological Responses and Associated Factors during the Initial Stage of the 2019 Coronavirus Disease (COVID-19) Epidemic among the General Population in China. International journal of environmental research and public health. 2020;17(5).

15. Park SC, Park YC. Mental Health Care Measures in Response to the 2019 Novel Coronavirus Outbreak in Korea. Psychiatry investigation. 2020;17(2):85-6.

16. Phillipson M, Roche M. Phenomenology, sociology, and the study of deviance 1. Deviance: Routledge; 2018. pp. 125-62.

17. Van Manen M. Researching lived experience: Human science for an action sensitive pedagogy: Routledge; 2016.

18. Van Manen M. Researching lived experience: Human science for an action sensitive pedagogy: Suny Press; 1990.

19. Lincoln Y, Guba E. Naturalistic Inquiry. Newbury Park: Sage Publications; 1985.

20. Navab E, Negarandeh R, Peyrovi H. Lived experiences of Iranian family member caregivers of persons with Alzheimer's disease: caring as 'captured in the whirlpool of time'. Journal of clinical nursing. 2012;21(7-8):1078-86.

21. Shafiei N, Abdeyazdan G, Sasani L, Abedi H, Najafi M. family care giving needed elderly with alzimehr(A phenomenological study. Journal of Clinical Nursing Midwifery. 2017;6(2):147-50.

22. Lin F-Y, Rong J-R, Lee T-Y. Resilience among caregivers of children with chronic conditions: a concept analysis. Journal of Multidisciplinary Healthcare. 2013;6:323.

23. Brandstätter M, Kögler M, Baumann U, Fensterer V, Küchenhoff $H$, Borasio GD, et al. Experience of meaning in life in bereaved informal caregivers of palliative care patients. Support Care Cancer. 2014;22(5):1391-9.

24. Kim Y. Nurses' experiences of care for patients with Middle East respiratory syndrome-coronavirus in South Korea. Am J Infect Control. 2018;46(7):781-7.

25. Essandor N. Loneliness in the elderly family caregiver. 2012.

26. Soylu C, Ozaslan E, Karaca H, Ozkan M. Psychological distress and loneliness in caregiver of advanced oncological inpatients. J Health Psychol. 2016;21(9):1896-906. 
27. Rokach A, Findler L, Chin J, Lev S, Kollender Y. Cancer patients, their caregivers and coping with Ioneliness. Psychology health medicine. 2013;18(2):135-44.

28. McRae C, Fazio E, Hartsock G, Kelley L, Urbanski S, Russell D. Predictors of loneliness in caregivers of persons with Parkinson's disease. Parkinsonism Relat Disord. 2009;15(8):554-7.

29. Navab E, Negarandeh R, Peyrovi H, Navab P. Stigma among I ranian family caregivers of patients with A Izheimer's disease: A hermeneutic study. Nurs Health Sci. 2013;15(2):201-6. 